\title{
Uma comunidade vulnerável, a necessidade de desenvolver conceitos para serviços aplicados a dispositivos móveis e um método: "Magic Thing".
}

Andrea Castello Branco Júdice, Marcelo Ortega Júdice

\begin{abstract}
In this paper the researchers describe the use of the "Magic Thing" method in a community in Rio de Janeiro. The method was applied aiming to comprehend the Community Health Agents expectations and needs involved on using mobile apps. The method was developed in Helsinki and used in a different context. Even applying in different situations, the method was an important tool to researchers reach new point of view and insights.
\end{abstract}

KeYwords: Magic Thing; mobile application; community.

\section{Resumo}

Neste artigo os pesquisadores relatam a aplicação, em uma comunidade do Rio de Janeiro, de um método chamado magic thing. Esse método foi aplicado na fase em que havia necessidade de compreender as reais expectativas e necessidades das Agentes Comunitárias de Saúde em relação ao uso de aplicativos móveis. 0 método foi desenvolvido em Helsinki e foi aplicado em contextos diferentes do foco deste artigo, mas apesar das diferenças o mesmo se mostrou adequado trazendo resultados surpreendentes que levaram os pesquisadores a um ponto de vista diferente e a novos insights.

Palavras-chave: Magic Thing, aplicativo móvel, comunidade. 


\section{Introdução}

Este artigo relata a experiência de aplicação do método Objeto Mágico (Magic Thing - lacucci, Giulio.; Kuuti, Kari; Ranta, Mervi; 2002) e suas implicações para o desenvolvimento de um aplicativo e/ou serviço em/para uma comunidade vulnerável'. Descreveparte doprojetodesenvolvido em uma comunidade de Duque de Caxias, Rio de Janeiro, que teve como foco a produção de sistemas de informação de alta e baixa tecnologia que auxiliem na melhoria da saúde. Esse método, com base no design participativo escandinavo (EhnctSjögren 1991, Bødker\&Grønbæk 1991, Greenbaum\&tKyng 1991), é aplicado em situações reais para que designers e usuários possam vislumbrar situações e entender a sequência em que os fatos acontecem para desenvolverem futuros cenários.

0 trabalho se centra no desenvolvimento deconceitos e cenários para serviços aplicados adispositivos móveis, considerando a participação e comprometimento dos diferentes usuários como forma de resolver os desafios encontrados neste contexto. 0 objeto mágico se adequa a essa situação por ser uma ferramenta aplicadasem foco específico, não impõe delimitação e restrições, permite o inesperado. A ideia do objeto mágico é não pré-determinar uma tarefa, mas sim seguir o usuário e experimentar com ele as situações impostas a ele, normalmente, em seu dia-a-dia, no contexto real. Como usuário e pesquisadores vão a campo livremente, cria-se um contexto compartilhado aonde as necessidades do usuário são entendidas e exploradas em situações reais, fazendo com que o pesquisador participedireta e indiretamente da realidade do usuário sem controle da situação e sem uma visão enviesada/estereotipada da situação. 0 usuário, por sua vez, não fica passivo ou tímido, se sente confortável em seu contexto, no controle da situação pois é o contexto em que ele vive e domina, com isso compartilha muito mais informações e se permite sonhar mais e mostrar suas reais necessidades, permitindo, também, que o pesquisador faça parte de seu mundo, naquele momento. Outros dois pontos interessantes a serem ressaltados são: o baixo custo para o desenvolvimento do objeto mágico; e por não ter funções e formas pré-definidas ajudaaos usuários a se relacionarem e apontarem conceitos e funções de produtos para a sua própria experiência e, portanto, preencheparte das lacunas entre a experiência atual e futura utilização. (lacucci, Giulio.; Kuuti, Kari; Ranta, Mervi; 2002; Hagen, Robertson, Kan, Sadler, 2005;Koskinen, Zimmerman, Binder, Redstrom\&tWensveen, 2011).

\section{Contexto do ambiente de aplicação do Objeto Mágico: Vila Rosário}

Vila Rosário² é uma comunidade localizada no Segundo Distrito do município de Duque de

1 Utilizamos a palavravulnerável seguindo o conceitoaplicadoporMargolinctMargolin no artigoA "Social Model" of Design: IssuesofPracticeandResearch Victor Margolinand Sylvia Margolin - Design Issues: Volume 18, Number 4 Autumn 2002. 2 Vila Rosário é a denominação utilizada no Instituto Vila Rosário para o contexto de atuação do projeto, mas o projeto abrange uma area maior que o bairro de Vila Rosário. Vila São José, Parque Fluminense e Parque Muisa, bairro Pantanal, 
Caxias, no estado do Rio de Janeiro. Tem aproximadamente 60.000 habitantes(Costa Neto \&t Castello Branco, 2007:43), com uma condição socioeconômica baixa, um nível educacional igualmente baixo, além de moradiasinsalubres e outros problemas como oalto grau de adictos de drogas e álcool. Apresentavam alto nível de tuberculose e de doenças tropicais quando o projeto foi iniciado (Costa Neto, 2002). Como em outras comunidades "invisiveis"3 a maioria dos moradores da comunidade de Vila Rosário, tem pouco acesso à novas tecnologias de informação e comunicação.

As pessoas que pertencem a comunidades como Vila Rosário, muitas vezes, são estigmatizadas ${ }^{4}$, algumas pessoas, que não fazem parte da comunidade, os veem por um ponto de vista muito estereotipado. Este tipo de comportamento faz com que o trabalho dos pesquisadores se torne mais difícil, porque os membros da comunidade acabam por ficar receosospara comentarem sobre a realidade em que vivem, principalmente quando estão frente aos pesquisadores. Quando conseguem falar sobre sua situação, é difícil ter um entendimento mais aprofundado sobre o real contexto em que vivem, pois a população prefere omitir questões importantes. Na percepção dos moradores, as questões como, por exemplo, as relacionadas à tuberculose, à higiene, às drogas, entre outras, podem torná-los ainda mais estigmatizados.

Quando designers-pesquisadores pensam em um contexto como o de Vila Rosário se perguntam: Como ter acesso e coletar informações de um grupo de pessoas consideradas de uma comunidade "invisivel" / estigmatizada? Como ter acesso aos dados de uma comunidade rodeada de miséria, HIV, tuberculose, entre outros fatores, e que não se vê e não é vista como parte de uma sociedade dita desenvolvida?

No início do trabalho, junto às pessoas que vivem em Vila Rosário, observou-se nos primeiros comentários destes membros da comunidade, que estariam dispostos a cooperar, mas para isso precisariam ter maior confiança nos pesquisadores. Somado a isso, salientaram que necessitavam queas soluções propostas/desenvolvidasfossem baseadas nas experiências e perspectivas da comunidade, não na perspectiva imposta por designers-pesquisadores. Essa colocação ressalta que muitas vezes há inadequação dos métodos, procedimentos e ferramentas aplicados o que faz com que pesquisadores não conheçam o contexto profundamente. Muitos pesquisadores, por não conhecerem/viverem o contexto, por não saberem envolver os usuários e por acessarem as informações adequadas ao desenvolvimento dos projetos elaborem soluções baseadas numa visão simpática e não em um design empático (KOSKINEN; BATTARBEE; MATTELMÃKI, 2003).

Frente a uma situação como esta os designers, ao serem desafiados a desenvolverem soluções para comunidades vulneráveis, geralmente, se questionam sobrequal é a forma

\footnotetext{
Parque Comercial e bairro São Bento também fazem parte do projeto. (Claudio Costa Neto - Vila Rosário um lugar onde se busca resgatar a dignidade de uma sociedade 2002 - livro)

3 (Durante as entrevistas com membros da comunidade, estes ressaltaram que se sentiam "invisiveis" pois se sentiam excluidos da sociedade dita "desenvolvida". Na opinião deles, muitas vezes eles não são vistos, não se sentem parte da sociedade. Esse pensamento corroborao conceito de invisível do FUNDO DAS NAÇÕES UNIDAS PARA A INFÂNCIA-UNICEF, 2007, são crianças e adolescentes que não têm acesso adequado à educação, à saúde e ao saneamento básico, entre outros, correndo o risco de serem excluídos da participação plena da sociedade.)

4 Estigma: a situação do indivíduo que está inabilitado para a aceitação social plena. (Goffman,2008)
} 
mais adequada para coletar informações acerca do usuário: o que os usuários querem e esperam do produto/serviço? Que tipo de experiência os usuários esperam e sonham ter ao possuírem e/ ou utilizarem este produto? Mas, infelizmente, na hora de responder a estes questionamentossão os especialistas de mercado, outsiders do contexto, baseados em questionários e técnicas de investigação específicas ao mercado, que respondem. Por estarem distantes da realidade da comunidade, não conseguem captar questões relativas à cultura local e não empregam métodos e técnicas que realmente tragam a comunidade para o contexto de co-experiência (Battarbee, 2004).

Num contexto diferenciado como o de Vila Rosário, novas questões surgem o tempo todo: Como fazer com que técnicas de investigação funcionem bem em comunidades vulneráveis? É necessário desenvolver/aplicar novos métodos, técnicas, procedimentos e ferramentas para mapear o contexto real? Pesquisadores conseguem/sabem captar amostras representativas das comunidades?Conversando com membros da comunidade os pesquisadores constataram que partes da vizinhança de Vila Rosário nunca receberam a visita de pesquisadores e os moradores creditam isso ao fato da região ser muito pobre, suja e perigosa.

Quando designers desenvolvem projetos para comunidades vulneráveis, especialmente no dito mundo em desenvolvimento, é necessário ter empatia (colocar-se no lugar do outro) e buscar um verdadeiro entendimento acerca das experiências do dia-a-dia dos membros da comunidade. Mais especificamente, é necessário entender o que eles sonham e desejam. Pesquisas "tradicionais" podem ser um início, exploratório, contudo designers/pesquisadores necessitam de outros tipos de informações para "mapear" o contexto e achar novas oportunidades para os projetos que possam ser desenvolvidos neste (para este) contexto.

As comunidades estudadas são populações com problemas que podem ser aliviados e resolvidos com o uso apropriado de soluções de design. Uma vez que designers não costumam ter sua origem neste tipo de comunidade, e mesmo se têm, as comunidades variam, assim é preciso entender profundamente o contexto de cada comunidade. Mattelmäki (2006), realça a necessidade da contribuição dos usuários com dados para inspiração dos designers, e da participação dos usuários ajudandoos designers a terem insights e desenvolverem soluções de design que sejam adequadas à realidade do contexto pesquisado.

Conforme Sanders (1999), deve-se estudar o que as pessoas dizem (say), fazem (do) e executam (make). Quando se investiga o que as pessoas dizem, entende-se melhor o que estão pensando. Quando busca-se entender o que elas fazem, entende-se como elas usam o produto. Quando se pede para que as pessoas executem alguma coisas, compreende-se melhor o que elas sabem, o que elas sentem, o que elas realmente necessitam e com o que elas sonham.

\section{Desenvolvimento do trabalho de campo: Aplicação do Objeto Mágico}

A pesquisa e o trabalho junto à comunidade foi extenso, tendo como um dos focos iniciaisas Agentes Comunitárias de Saúdedo Instituto Vila Rosário (ACS-IVR)por serem um 
link importante na comunicação entre membros da comunidade e os outros stakeholders envolvidos no projeto.

0 método do objeto mágico foi aplicado após várias etapas de aprofundamento no conhecimento do contexto de Vila Rosário, da cultura local e da vida de membroschave para o projeto, destacando as Agentes Comunitárias de Saúde do IVR. Os métodos anteriores foram baseados no design Participativo Escandinavo(EHN \& SJÖGREN, 1991; BØDKER \& GRØNBAK, 1991; GREENBAUM \& KYNG, 1991), no Design Empático Finlandês (KOSKINEN; BATTARBEE; MATTELMÃKI, 2003) e métodos de usabilidade (LINDHOLM; KEINONEN; KILANDER, 2003).

\section{Figura 1: Etapas de desenvolvimento do Objeto Mágico (desenvolvido a partir de Giulio lacucci)}

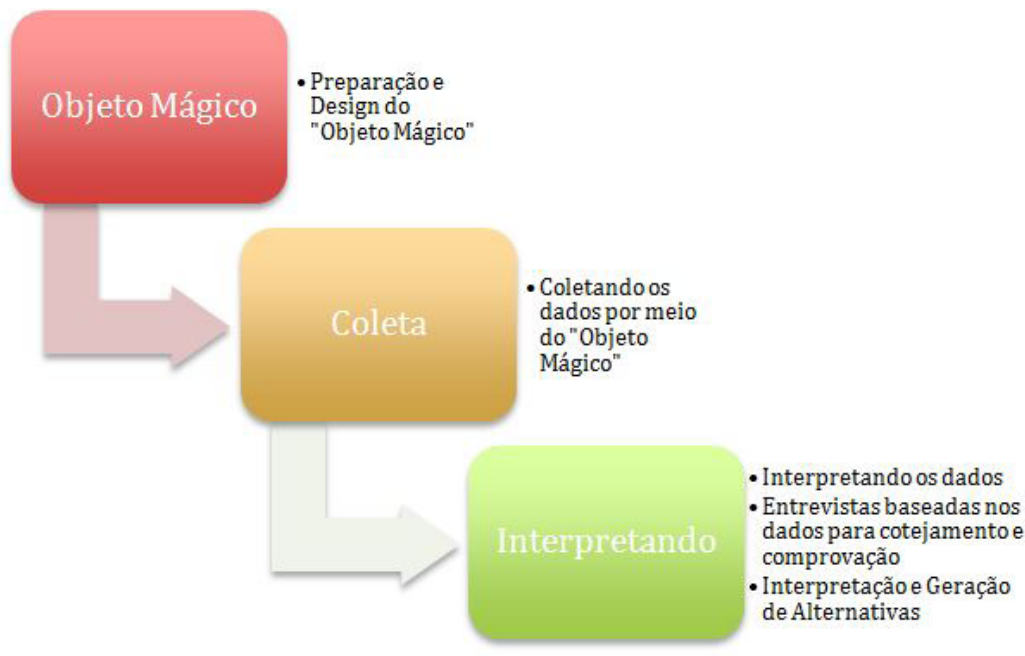

Por intermédio dos dados coletados em etapas anteriores, foi possivel identificar diferentes contextos e necessidades diversas (agentes comunitárias de saúde, membros da comunidade, médicos, voluntários, entre outros.). Como se imaginava, foi possível reconhecer que soluções de baixa complexidade tecnológica se mostraram mais adequadasaos membros da comunidade, mas para os especialistas as soluções envolvendo alta tecnologia se mostram mais eficazes. Esse resultado direcionou ao método do objeto mágico para a presente etapa. Por ser um métodoaberto, de baixo custo, que permite ter um aprofundamento das 3 fases propostas por Sanders (1999, Say, Do, Think), ser simples de desenvolver e de adequar ao contexto se encaixa perfeitamente à busca de conceitos e soluções para novos serviços aplicados a dispositivosque possam dar suporte ao trabalho das agentes comunitárias de saúde do IVR. Objetivando contextualizar o público alvo desta etapa, segue abaixo uma breve descrição do trabalho das Agentes Comunitárias de Saúde do IVR. 
Para ser um agente comunitário do IVR, as características e requisitos que as agentes devem ter são:comprometimento com a comunidade; necessitam residir na área em que pretendem atuar; saber ler, escrever e se comunicar com os médicos e com os membros da comunidade.

De forma geral, a agente comunitária de saúde do IVR realiza atividade de prevenção de doenças tropicais e promoção da saúde sob supervisão doscoordenadores do Instituto. Como atribuições básicas, podemos elencar as principais: realização ações educativas em relação ao planejamento familiar, saúde da mulher, criança e adolescentes, monitoramento de doenças infectocontagiosas, dermatoses, parasitoses, acompanhamento das micro áreas de risco, participação no levantamento do diagnostico demográfico das comunidades, visitas familiares de acompanhamento, entre outras muitas atribuições. As agentes comunitárias de saúdedesempenham um papel importante na comunidade, os membros da comunidade confiam no trabalho delas, o que facilita o trabalho dos pesquisadores. A comunidade se compromete com a pesquisa.

Abaixo, para ilustrar as 4 principais etapas do trabalho das Agentes - ACS-IVR e exemplificar o presente artigo com um dos produtos resultantes da experiência prévia de aplicação do design empático finlandês, uma tirinha, em quadrinhos, desenvolvida com as Agentes. A tirinha virou parte do uniforme delas, haja vista a necessidade que têm de explicar aos moradores as principais fases do trabalho que desenvolvem.(Figura2: Principais etapas do trabalho das agentes comunitárias de saúde. Ilustração desenvolvida com e para as agentes.).

Figura 2: Principais etapas do trabalho das agentes comunitárias de saúde. Busca ativa - encaminhamento para o tratamento adequado - orientação família e amigos - acompanhamento.
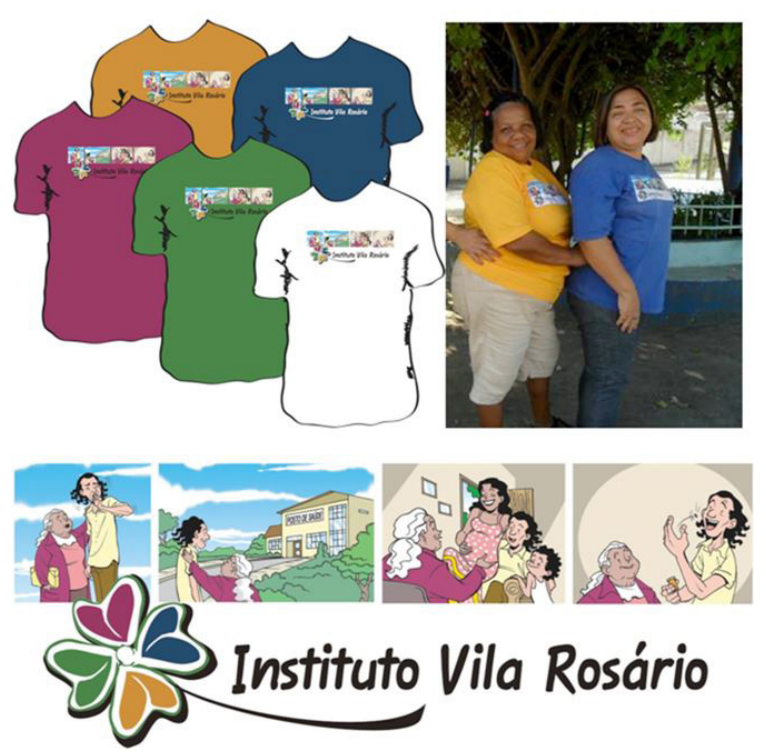


\section{0 método em contexto}

A abordagem para a aplicação do objeto mágico se deu pelo acompanhamento das atividades das agentes comunitárias de saúde durante um dia de seu trabalho. As atividades foram anotadas em um diário, com observações sobre mapas e rotas de mobilidade, foram feitos registros fotográficos, em vídeo eentrevistassemi estruturadas aliadas a técnica de "Thinkaloud" (pense alto). A ideiafoi documentar todos os fatos e observar tudo que acontecia no contexto, ressaltando as situações mais interessantes. Os designers, neste momento, têm que ter a habilidade e competência para identificar quais fatores estão contribuindo para os problemas que a comunidade enfrenta. (e.g. saneamento básico inadequado, má nutrição, entre outros.). Neste ponto do estudo a questão norteadora foi: que tipos de produtose serviços encontram/respondem as necessidades desta comunidade. (MARGOLINCAMARGOLIN, 2002).

Durante todo o dia as agentes de saúde carregavam o mock-up de um dispositivo móvel (um objeto mágico) que era para ser usado como um dispositivo portátil que pudesse ajudá-las em situações de resoluções de problemas ou situaçõesespecíficas que necessitassem de ajuda envolvesse decisão de terceiros. 0 mock-up foi desenvolvido com base nos dados coletados e tratados nas etapas anteriores. A partir do entendimento aprofundado do contexto e de uma maior compreensão da atividade das agentes comunitárias de saúde, os pesquisadores chegaram ao tamanho e ao formato ideal do objeto mágico a ser testado em campo. Esse é um método aberto, então nada além, do formato e do tamanho, foi especificado. As agentes poderiam utilizar na hora que achassem necessário e da maneira que melhor lhesatendesse. Conforme foi descrito por uma agente como: "usando o objeto mágico como um assistente para entrar em contato com pessoas das emissoras de TV".

Ao passar em frente a duas casas com os pesquisadores, uma das agentes comunitárias parou e começou a descrever a seguinte situação:

Outro dia, uma moça veio até mim para reclamar: "minha filha, essa é a fossa da minha vizinha, quando ela dá descarga ela enche o meu jardim de água suja. Eu estou enlouquecendo com essa situação! Eu não sei mais o que fazer! Eu tenho medo que eu, ou alguma outra pessoa da minha familia pegue hepatite. Eu tenho crianças e tenho que ter cuidado o tempo todo!

Minha filha me digao que eu posso fazer para me prevenir e prevenir minha família de doenças numa situação como essa?"

Naquele momento (disse a agente comunitária de saúde) eu me senti sem forças, impotente! Então, eu perguntei à senhora: "minha senhora, a senhora já foi à prefeitura ou a outros órgãos competentes em busca de solução para essa situação?" Sim, respondeu à senhora, e o que eles me disseram é que atualmente eles não podem fazer nada com relação a essa situação.

A rua onde essa senhora vive, como vocês podem ver, é asfaltada no início e no final, mas 
no meio não há asfalto. Para mim, essa terra, antes de ter casas era um pântano, onde os moradores jogaram areia e começaram a construir as casas deles sobre esse terreno. Por isso a falta de infra estrutura. Essa senhora tem um bebê de 2 meses, uma garotinha de 4 anos, um garoto de 6 anos e um menininho de 1 anos e dez meses. Num dia desses as crianças dela e mais alguns amigos(cerca de 5 amigos) estavam brincando no jardim, nessas condições precárias. Por causa da ausência de saneamento básico adequado, essa rua é um foco de muitas doenças como, leptospirose, hanseniase, hepatite, entre outras. Eu mesma já tomei conta de duas pessoas com tuberculose severa, 3 com leptospirose, algumas com hepatite, doenças de pele e outras.

Agentes Comunitárias de Saúde e membros da comunidade sabem que o grande problema é a falta de saneamento básico adequado. Andando pela rua você fica apavoradocom a quantidade de mosquito. Eu tenho quase certeza que você pode achar o mosquito transmissor da dengue (Aedes aegypti). Outro dia, você acredita que até uma cobra eu achei aqui! É claro que essa é uma situação extremamente insalubre, especialmente para crianças. Eu gostaria de ter mais ajuda de outras instituições, ou de agências e órgão responsáveis para mudar essa situação.

Então, seu eu tivesse esse objeto mágico e ele pudesse fazer o que eu quisesse, naquele momento em que a senhora me perguntou o que fazer frente àquela situação, eu pegaria o meu objeto mágicoe pediria que ele me mostrasse/me colocasse em contato com pessoas que me ajudassem a mudar essa situação. Eu gostaria de apertar um botão no meu objeto mágico e nesse momento o objeto mágico trouxesse até mim ou me colocasse em contato com pessoas da Televisão. Pessoas para as quais eu pudesse explicar a nossa situação e eles se sensibilizariam com o problema. Pois, mesmo se eles não pudessem estar aqui eles veriam a situação pelo objeto mágico. Eu tenho certeza de que eles entenderiam nossa situação e poderiam fazer uma entrevista mostrando a nossa situação para sociedade. Eu creio que com essa entrevista alguém importante iria assistir e viria nos ajudar!

Nesse relato de uso do objeto mágico foi importante observar que tipo de funções e para que tipos de uso a agente comunitária de saúde do IVR gostaria de ter o objeto mágico e, entender que tipos de soluções ela enxerga como adequadas à situação atual da comunidade. Esse foi um ponto muito interessante da aplicação do objeto mágico, pois, dificilmente os designers-pesquisadores pensariam em desenvolver um botão que colocasse as agentesconectadas as redes de televisão. Relevante, também, éperceber 0 valor e o poder da mídia para comunidade.

Outra situação a ser ressaltada aconteceuquando uma das agentes apontou para duas ruas e mostrou que entre essas duas ruas existe um grande valão (esgoto a céu aberto) e que algumas semanas antes ocorrera um surto diarreico e, os médicos não conseguiam perceber porque o surto havia acontecido. A agente mostrou um mapa (figura 3), que estava sendo desenvolvido por ela e uma outra agente, no qual elas marcam as doenças 
que estão ocorrendo, em qual locale o porquê elas achavam que estas doenças estavam ocorrendo. Neste momento, a agentesegurou o objeto mágico e verbalizou que gostaria que este dispositivo pudesse fotografar e filmar a área e o contexto, além de poder descrever suas opiniões e impressões e enviar os resultados diretamente aos médicos e aos responsáveis pelo saneamento da região para que eles tomassem as devidas providencias. Na simulação (figura 4) que os pesquisadores realizaram para corroborar o que a agente gostaria de obter com objeto mágico, foi possivel identificar que a agente tiraria fotos não apenas do valão, mas também das pessoas que habitam e frequentam o local destacando suas maneiras de vestir/de calçar, seus comportamentos, fotos das casas da região destacando problemas que podem causar e/ou piorar a situação da doença, entre outros fatores relevantes para entendimento mais aprofundado da situação. Na verbalização, que elas enviariam aos médicos junto às fotos e à localização no mapa, elas passariam as informações necessárias aos médicos para fecharem um diagnóstico. Ambos, médicos e agentes, tendo o objeto mágico poderiam prontamente tirar dúvidas, ter mais imagens do local, fazerem entrevistas, entre outras ações para resolver a situação. Na opinião da agente esse objeto mágico único, que seria fácil de carregar, guardar na sua bolsa de agente e fácil de interagir, poderia não apenas ajudar a tratar doenças, mas prevenir e combater males que acometem a comunidade. Nesse momento a agente destacou vários outros serviços que elas prestam a comunidade que devem ser ampliados e mais divulgados principalmente por meio de aplicativos móveis, como por exemplo: cursos de nutrição, cuidados com a casa, prevenção de doenças e acidentes em casa, entre outros.

Figura3: Simulação do que a agente comunitária de saúde gostaria de que fosse enviado aos responsáveis pela saúde e saneamento na região.

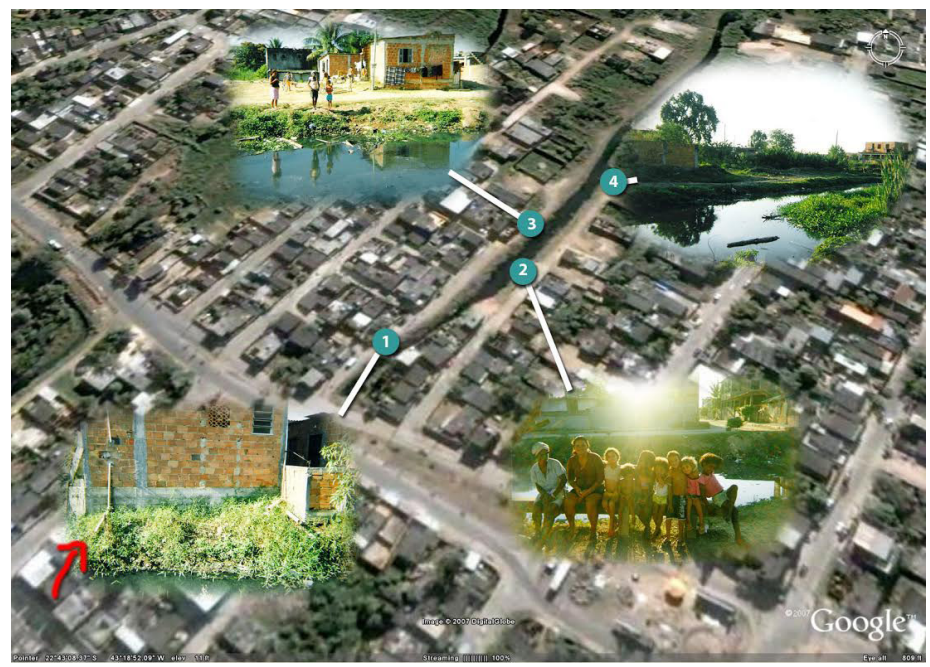




\section{Considerações sobre o aprendizado a partir da aplicação do objeto mágico}

A aplicação do método objeto mágico permitiu que os pesquisadores tivessem diferentes insights acerca da situação da comunidade. 0 entendimento da mobilidade das agentes não ficou restrito aos aspectos geográficos / mobilidade física e de navegação, nem ao modo como as agentes acessam e transmitem informações. Também foi abordado o modo como as agentes querem utilizar e o que elas querem que tenha num dispositivo móvel, os diferentes tipos de comunicação na/da comunidade , como a comunicação é organizada e como ocorre na/para comunidade e como as socializações acontecem no contexto estudado. Os resultados obtidos nesta parte do estudo reforçaram alguns pontos importantes já levantados a partir de outros métodosetrouxeram novos insights sobre hábitos daquele grupo social, da cultura local, de comportamentos, de crenças, entre outros.

Durante a aplicação do método, ficou claro que o acesso às informações e o modo de aplicação do método devem ser negociados e acordados previamente com todos os envolvidos. A observação direta, com câmeras de foto e vídeo e mesmo a anotação podem gerar constrangimentos, modificar o comportamento e até mesmo afastar participantes. Assim, deve ser estabelecido um acordo que traga em seu bojo um equilíbrio entre a privacidade dos participantes e as necessidades dos pesquisadores. No caso da presente pesquisa não ocorreu esse tipo deproblema haja vista otempo que os pesquisadorestêm deenvolvimento com a comunidade, por já terem conquistado um espaço e por terem a confiança dos envolvidos na pesquisa. Em locais públicos, que outras pessoas estavam expostas, os pesquisadores, por já conhecerem as regras locais e a cultura da comunidade, sabiam quando podiam ou não utilizar todos os instrumentos de pesquisa.

\section{Agradecimentos}

Os autores são gratos a: IlpoKoskinen, Cláudio Costa Neto, Luiz Roberto Castello Branco e TuuliMattelmäki, pelo suporte e enriquecedores comentários e orientações; aos participantes da comunidade que contribuem constantemente para o aperfeiçoamento da qualidade do projeto; ao CNPq - Conselho Nacional de Desenvolvimento Científico e Tecnológico, por ter dado suporte financeiro durante o decorrer de seus projetos de doutorado.

Somos gratos ao Instituto Vila Rosário, em especial às agentes comunitárias de saúde, aos membros da comunidade que tanto nos apoiaram. Agradecemos, também, à Universidade Aalto (Finlândia) e ao Núcleo de Multimídia e Internet da Universidade de Brasília. 


\section{Referências}

BATTARBEE, Katja. Co-experience: Understanding user experiences in social interaction. 1st Helsinki: Univesity Of Art And Design Helsinki, 2004. 217 p.

BØDKER S \& GRØNB/EK K (1991) Design in Action: From Prototyping by Demonstration to Coopera- tive Prototyping. In Greenbaum J CtKyng M (eds) Design at Work: Cooperative Design of Computer Systems. Hillsdale, NJ: Lawrence Erlbaum Associates, 197-218.

COSTA NETO, C. 2002. Vila Rosário. Cálamo Produção Editorial. Rio de Janeiro

COSTA NETO, C., CASTELLO BRANCO, L. 2007. Use of Science and Technology toRedesign. A societyaimingateliminatingpoverty. In: Miettinen, S. (ed.): Design youraction: Social Design in Practise. UniversityofArtand Design Helsinki pp.42-43

EHN P \& SJÖGREN D (1991) From System Description to Scripts for Action. In: Greenbaum and Kyng, 241-269.

FUNDO DAS NAÇÕES UNIDAS PARA A INFÂNCIA-UNICEF (Ed.). Situação Mundial da Infância 2006: Excluídas e Invisiveis. Disponivel em:<http://www.unicef.pt/18/relatorio_sowc06.pdf>. Acesso em: 15 ago. 2007.

GOFFMAN, Erving. Estigma: notas sobre a manipulação da identidade deteriorada. 4a Rio de Janeiro: Ltc, 2008. $158 \mathrm{p}$.

GREENBAUM. JCtKYNG M (1991) Design at work: cooperative design of computer systems, Hillsdale, NJ, Lawrence Erlbaum.

HACKOS, Joann T.; REDISH, Janice C. (Ed.). User and Task Analysis for Interface Design. New York: John Wiley \& Sons, 1998. 304 p.

ROBERTSON, T., KAN, M., SADLER, K., \& HAGEN, P., (2005): Uncovering traces of mobile practices: 'the bag study'. In: Proceedingsof OZCHI05.

IACUCCI, Giulio; KUUTTI, Kari\&t RANTA, Mervi. 2000. Onthe move with a magicthing: role playing in concept design of mobile servicesanddevices. In Proceedingsofthe $3 \mathrm{rd}$ conferenceonDesigninginteractive systems: processes, practices, methods, andtechniques (DIS '00), Daniel Boyarskiand Wendy A. Kellogg (Eds.). ACM, New York, NY, USA, 193-202.

KOSKINEN, Ilpo; BATTARBEE, Katja; MATTELMÃKI, Tuuli (Ed.). Empathic Design: User Experience in Product Design. Finland (edita): It Press, 2003. 168 p.

KOSKINEN, jllpo; ZIMMERMAN, John; BINDER, Thomas; REDSTROM, Johan; WENSVEEN, Stephan.

Design ResearchThroughPractice: FromtheLab, Field, and Showroom. 1st Morgan Kaufmann, 2011.

LINDHOLM, Christian; KEINONEN, Turkka; KILANDER, Harri (Ed.). Mobile Usability: How Nokia

Changed the face of the mobile phone. 1st New York: Mcgraw-hill, 2003. 304 p.

MARGOLIN, Victor \& MARGOLIN, Sylvia. A "Social Model" of Design: IssuesofPracticeandResearch. Design Issues 2002 18:4, 24-30

MATTELMÄKI, T. 2006. Design Probes. D.A. dissertation, Industrial and Strategic Design Department, University of Art and Design Helsinki, Finland.

SANDERS, Elizabeth. 2002.FromUser-CenteredtoParticipatory Design Approaches. Disponivel em:<http://www.maketools.com/articles-papers/FromUsercenteredtoParticipatory_Sanders_\%2002.pdf>. Acessoem: 10 jun. 2005. 



\section{Estudios}


